\title{
Pelatihan Dasar Animasi Menggunakan Macromedia Flash Pro 8.0 Untuk Warga RT.010 Mampang Prapatan Jakarta Selatan
}

\author{
Andi Saryoko ${ }^{1}$, Kresna Ramanda ${ }^{2}$, Susy Rosyda $^{3}$, Retno Sari $^{4}$, Ridwansyah $^{5}$ \\ 1,2,3,4,5 Sekolah Tinggi Manajemen Informatika dan Komputer Nusa Mandiri \\ Jalan Jatiwaringin No.2 RT.8/RW.13, Cipinang Melayu, Kec. Makasar, Kota Jakarta Timur, \\ Daerah Khusus Ibukota Jakarta, Indonesia \\ e-mail: ${ }^{1}$ andi.asy@ nusamandiri.ac.id, ${ }^{2}$ kresna.kra@ nusamandiri.ac.id, \\ ${ }^{3}$ susy.sud@nusamandiri.ac.id, ${ }^{4}$ retno.rnr@nusamandiri.ac.id, \\ 5ridwansyah.rid@nusamandiri.ac.id
}

\begin{abstract}
Abstrak
Saat ini penggunaan Teknologi Informasi di masyarakat sudah menjadi hal sehari- hari yang digunakan, tetapi pengetahuan mengenai ICT belum semua masyarakat mengetahuinya secara maksimal. Dosen dan PPPM (Pusat Penelitian dan Pengabdian Masyarakat) Sekolah Tinggi Manajemen Informatika dan Komputer Nusa Mandiri ingin melakukan pengabdian masyarakat dengan tema Pelatihan Dasar Animasi Menggunakan Macromedia Flash Pro 8.0 Untuk Warga RT.010 Mampang Prapatan Jakarta Selatan. Kami selaku Dosen dan PPPM (Pusat Penelitian dan Pengabdian Masyarakat) Sekolah Tinggi Manajemen Informatika dan Komputer Nusa Mandiri ingin melakukan pengabdian masyarakat dengan memberikan pelatihan kepada Anak-anak warga RT.010 Mampang Prapatan Jakarta Selatan dengan tema Pembelajaran Design Animasi Menggunakan Macromedia Flash 8.0 Untuk Anak-Anak Warga Dilingkungan RT.010 Mampang Prapatan Jakarta Selatan agar memiliki kemampuan membuat suatu animasi interaktif. Kemampuan dalam membuat animasi ini dapat menjadi modal mereka untuk dapat bersaing di era globalisasi ini.
\end{abstract}

Kata Kunci: Pelatihan, Macromedia Flash Pro 8.0, Warga RT.010 Mampang Prapatan

\begin{abstract}
Currently the use of Information Technology in society has become a daily use, but not all people know about it optimally. Lecturers and PPPM (Center for Research and Community Service) Nusa Mandiri School of Information and Computer Management want to do community service with the theme Basic Animation Training Using Macromedia Flash Pro 8.0 for residents of RT.010 Mampang Prapatan, South Jakarta. We as Lecturers and PPPM (Center for Research and Community Service) of the Nusa Mandiri School of Informatics and Computer Management want to do community service by providing training to the children of RT.010 Mampang Prapatan South Jakarta with the theme of Learning Animation Design Using Macromedia Flash 8.0 for Children -Children of RT.010 Mampang Prapatan South Jakarta to have the ability to create interactive animations. Their ability to make animation can be their capital to be able to compete in this globalization era.
\end{abstract}

Keywords: Training, Macromedia Flash Pro 8.0, Residents of RT.010 Mampang Prapatan 


\section{Pendahuluan}

Perkembangan dunia animasi komputer yang pesat dewasa ini memerlukan waktu puluhan tahun dalam proses penciptaannya. Animasi secara harfiah berarti membawa hidup atau bergerak. Secara umum, menganimasi suatu obyek memiliki makna menggerakan obyek tersebut agar menjadi hidup. Tidak bisa dipungkiri lagi dalam era globalisasi ini persaingan semakin cepat dan ketat. Oleh karena itu, Dosen menjadi Sumber Daya Manusia yang harus mampu memiliki peserta didik yang mampu bersaing untuk mengikuti perkembangan. Dunia Pendidikan Tinggi sangat berperan penting dalam mendorong pembangunan. Dalam UndangUndang Diknas pasal 20 UU No. 20 Tahun 2003 tentang Sistem Pendidikan Nasional menyatakan bahwa salah satu dharma Perguruan Tinggi, selain pendidikan dan penelitian, adalah kegiatan pengabdian masyarakat. Begitu juga pada pasal 24 UU Diknas menyatakan adanya otonomi Perguruan Tinggi untuk mengelola sendiri lembaganya sebagai pusat penyelenggaraan pendidikan tinggi, penelitian ilmiah, dan pengabdian kepada masyarakat. Tri Dharma Perguruan Tinggi itu sendiri merupakan tiga pilar utama penyelenggaraan institusi perguruan tinggi. Untuk menunaikan salah satu Tri Dharma tersebut, dengan ini Sekolah Tinggi Manajemen Informatika dan Komputer Nusa Mandiri melaksanakan Pengabdian Masyarakat. Hal ini dilaksanakan berkaitan dengan kepedulian setiap lembaga atau institusi yang bergerak di bidang pendidikan, khususnya Pendidikan Tinggi dengan mengikuti perkembangan dan kemajuan teknologi. Saat ini penggunaan Teknologi Informasi di masyarakat sudah menjadi hal sehari- hari yang digunakan, tetapi pengetahuan mengenai ICT belum semua masyarakat mengetahuinya secara maksimal. Dosen dan PPPM (Pusat Penelitian dan Pengabdian Masyarakat) Sekolah Tinggi Manajemen Informatika dan Komputer Nusa Mandiri ingin melakukan pengabdian masyarakat dengan tema Pelatihan Dasar Animasi Menggunakan Macromedia Flash Pro 8.0 Untuk Warga RT.010 Mampang Prapatan Jakarta Selatan. Oleh karena itu, kami selaku Dosen dan PPPM (Pusat Penelitian dan Pengabdian Masyarakat) Sekolah Tinggi Manajemen Informatika dan Komputer Nusa Mandiri melakukan pengabdian masyarakat dengan memberikan pelatihan kepada Anak-anak warga RT.010 Mampang Prapatan Jakarta Selatan dengan tema Pembelajaran Design Animasi Menggunakan Macromedia Flash 8.0 Untuk Anak-Anak Warga Dilingkungan RT.010 Mampang Prapatan Jakarta Selatan agar memiliki kemampuan membuat suatu animasi interaktif. Kemampuan dalam membuat animasi ini dapat menjadi modal mereka untuk dapat bersaing di era globalisasi ini.

Beberapa kajian jurnal pengabdian masyarakat antara lain:

Pelatihan Komputer Untuk Anak-Anak Yayasan Yatim Piatu Dan Sosial Irma Dalam Menghadapi Era 4.0 (Era et al., 2020), Sosialisasi Dan Pelatihan Penggunaan Internet Sehat Bagi Anggota Badan Usaha Milik Desa (Bumdes) Mozaik Desa Pematang (Hariyanto \& Wahyuni, 2020), Pemanfaatan IPTEK Dalam Kegiatan Belajar Mengajar Untuk Masyarakat Pela Mampang Di Masa Pandemi (Saryoko et al., 2020), Pemanfaatan Teknologi Informasi Untuk Meningkatkan Pelayanan Akademik Rumah Tahfidz Dan TPQ Sakinah Cipayung Jakarta Timur (Amalia et al., 2020)

Artikel pada jurnal di atas sangat berpengaruh pada pengabdian masyarakat yang kami lakukan. Selain menjadi referensi artikel-artikel tersebut dapat menjadi motifasi kami dalam melakukan pengabdian masyarakat.

\section{Metode}

Metode yang diterapkan terdapat dalam gambar 1: 


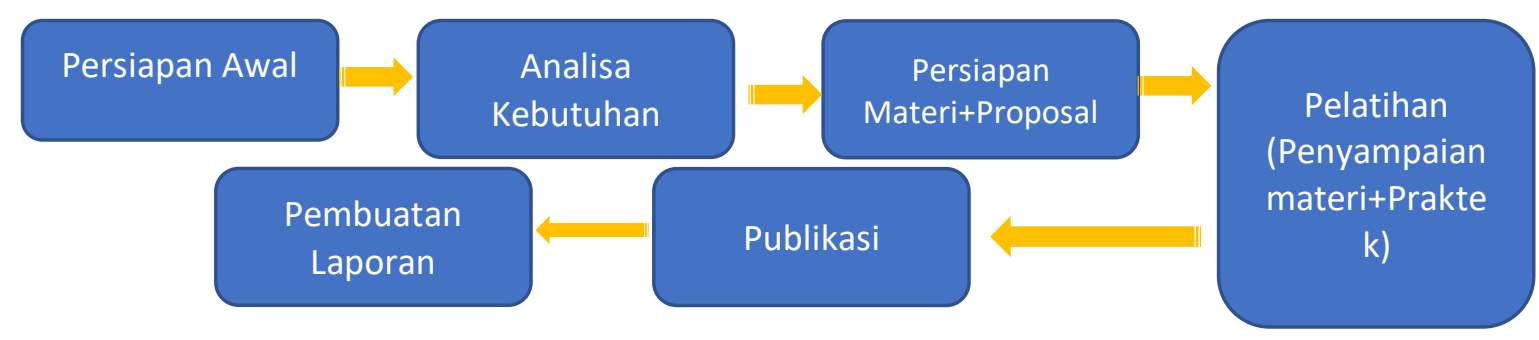

Gambar 1. Metode Pelaksanaan Pengabdian Masyarakat

Sebelum melakukan pengabdian masyarakat, hal yang harus dilakukan adalah melakukan persiapan dan selanjutnya melakukan analisa kebutuhan mitra yang bertujuan untuk mengetahui kebutuhan materi apa yang mitra butuhkan saat ini. Setelah sudah mengetahui kebutuhan materinya, maka proses selanjutnya adalah melakukan persiapan pembuatan materi dan proposal. Setelah semua persiapan selesai dilakukan, maka selanjutnya adalah proses pelatihan yang dilakukan penyampaian materi sekaligus praktik untuk mempraktekkan materi yang sudah disampaikan oleh mitra. Setelah pelatihan selesai maka dilakukan publikasi baik berupa press release atau berupa jurnal. Langkah terakhir adalah pembuatan laporan pengabdian masyarakat.

\section{Hasil dan Pembahasan}

Pelatihan dalam bentuk Kegiatan pengabdian masyarakat ini memberikan pengetahuan dan keterampilan dasar pembuatan animasi di kalangan anak-anak khususnya di wilayah RT. 010/ 003 Mampang Prapatan, agar peserta bisa memanfaatkan pembuatan animasi dengan semaksimal dan sebaik mungkin. Pengabdian masyarakat dengan memberikan pelatihan kepada Anak-anak warga RT.010 Mampang Prapatan Jakarta Selatan dengan tema Pembelajaran Design Animasi Menggunakan Macromedia Flash 8.0 Untuk Anak-Anak Warga Dilingkungan RT.010 Mampang Prapatan Jakarta Selatan agar memiliki kemampuan membuat suatu animasi interaktif.

Kegiatan pengabdian masyarakat yang dilakukan di wilayah RT. 010/ 003 Mampang Prapatan juga mempunyai luaran berupa Publikasi pada media masa (cetak/elektronik) yang saat ini sudah terbit publish pada http://lppm.nusamandiri.ac.id/warga-rt-010-mampangprapatan-jakarta-selatan-antusias-mengikuti-pelatihan-dasar-animasi-menggunakan-

$\underline{\text { macromedia-flash-pro-8-0/ }}$

\section{Kesimpulan}

Kegiatan pengabdian masyarakat ini dilaksanakan pada Hari Sabtu Tanggal 19 September 2019 dari jam 09.00 - 12.00 WIB di Aula RT. 010/ 003 Pela Mampang. Adapun panitia yang terlibat pada kegiatan pengabdian masyarakat, sebagai berikut: Penanggung Jawab Dr. Dwiza Riana, S.Si, MM, M.Kom, Ketua Pelaksana Andi Saryoko, M.Kom, Tutor Kresna Ramanda, M.Kom dan dibantu teman-teman yang lainnya, Susy Rosyida, M.Kom, Retno Sari, M.Kom, Ridwansyah, M.Kom, Gusti Wahyudin, Angga Novian Pradana. Peserta terdiri dari AnakAnak Warga Dilingkungan RT.010 Mampang Prapatan Jakarta Selatan dengan jumlah peserta sebanyak kurang lebih 30 orang.

Rasa terimakasih disampaikan oleh Ketua RT 010/ 003 Pela Mampang dengan diadakannya pengabdian masyarakat berupa Pelatihan Dasar Animasi Menggunakan Macromedia Flash Pro 8.0. Peserta juga sangat senang dengan kegiatan pelatihan Dasar Animasi. 


\section{Daftar Pustaka}

Amalia, H., Retnasari, T., \& Rachmawati, S. (2020). Pemanfaatan Teknologi Informasi Untuk Meningkatkan Pelayanan Akademik Rumah Tahfidz Dan Tpq Sakinah Cipayung Jakarta Timur. Jurnal Abdimas BSI: Jurnal Pengabdian Kepada Masyarakat, 3(2), 228-235. https://doi.org/10.31294/jabdimas.v3i2.8550

Era, M., Rosyida, S., Sari, R., Saryoko, A., \& Ramanada, K. (2020). Pelatihan Komputer Untuk Anak-Anak Yayasan Yatim Piatu Dan Sosial Irma Dalam. 2(1), 2-4.

Hariyanto, E., \& Wahyuni, S. (2020). Sosialisasi Dan Pelatihan Penggunaan Internet Sehat Bagi Anggota Badan Usaha Milik Desa (Bumdes) Mozaik Desa Pematang Serai. Jurnal Abdimas BSI: Jurnal Pengabdian Kepada Masyarakat, 3(2), 253-259. https://doi.org/10.31294/jabdimas.v3i2.8449

Saryoko, A., Sari, R., Rianto, V., \& Rosyida, S. (2020). Pemanfaatan IPTEK Dalam Kegiatan Belajar Mengajar Untuk Masyarakat Pela Mampang Di Masa Pandemi. ABDIMAS: Jurnal Pengabdian Masyarakat, 3(2), 304-310. https://doi.org/10.35568/abdimas.v3i2.920 